\title{
Use of Simulation in Visual Flight Training: The Effect on Time to Solo
}

\author{
Steven Goetz \\ Bryan Harrison \\ Michael Robertson \\ Southern Illinois University Carbondale
}

\begin{abstract}
The purpose of this study was to determine what effect the use of flight simulation has on the time to solo of student pilots. Participants in this study were first semester flight students at Southern Illinois University Carbondale (SIUC). Twelve participants completed the study and were given three hours of instruction in a Frasca 141 flight training device (FTD) with visual display prior to beginning training in an aircraft. The students were all instructed on the basic sight pictures of a Cessna 172, given instruction on aircraft control, basic maneuvers, and take-off and landing in the FTD. At the completion of first solo, the total flight time and calendar days to the first solo from the starting date were calculated and compared to a historic data group. The experimental group had a mean time to solo of 17.1 hours, mean days to solo of 77.3 days compared to the historic group which had a mean time to solo of 17.4 hours, mean days to solo of 86.1 days. These differences were not significant at the .05 level for hours $t(150)=.225, p=$ .823 (two-tailed), $1-\beta=.056, \eta^{2}=.000$; or days $t(150)=.784, p=.434$ (two tailed), $1-$ $\beta=.142, \eta^{2}=.004$.
\end{abstract}

\section{Introduction}

Simulation is used in numerous fields for multiple applications. It can be used to demonstrate difficult concepts to students in a physics classroom (Oss, 2005) or used to train medical practitioners to save lives (Bradley \& Postlethwaite, 2003). In many fields mistakes cost time and money but in aviation mistakes can cost lives. This leads to a large amount of simulation training being conducted in the aviation industry. At the primary level, simulation is used to teach basic concepts that are necessary for flight training in a controllable environment where the simulation equipment can change with the needs of the learner (Padfield \& White, 2003). In commercial aviation, especially in the airline environment, simulation is used to maintain currency and proficiency. Simulation can be used to experience unusual situations and become accustomed to different crew styles (Foushee, 1984). Simulation allows mistakes to be made in a controlled environment where consequences can be realized and learned from without the fear of loss of life. Aviation simulation also serves the role of reducing the cost of training. Airlines use simulators because it is significantly cheaper to train pilots in a device that consumes only electricity rather than one that consumes large quantities of jet fuel. 


\section{Significance of the Problem}

Flight training is a rewarding and expensive experience for those who undertake it. Comparing advertised training rates from around the United States (including rental rates and instructor fees) assuming 40 hours of flight time and 40 hours of instructor time, flight schools are charging between $\$ 6,000$, in the Midwest, and $\$ 9,000$, on the East and West coasts, for students to earn their private pilot certificate. These costs are for basic certification and not for beginning a career. To reach the point of employability at an airline individuals must obtain a commercial pilot certificate with multiengine and instrument ratings. The minimum training expenditure to obtain these certificates and ratings is between $\$ 50,000$ and $\$ 60,000$ (Airfleet Training Systems Inc., n.d.; California Flight Academy, 2003; Mid Island Air Service, 2009; St. Charles Flying Service, 2010; Airline Transport Professionals, n.d.).

When considering the financial burden to a student entering the flight community as a career, a student can expect to spend between $\$ 50,000$ and $\$ 60,000$ to reach a minimum level of employability. With the high initial financial obligation from the student, any cost reduction without compromising safety would be welcome. Simulation time tends to cost about half of what aircraft time costs (Airfleet Training systems Inc., n.d.; Mid Island Air Service, 2009). If $10 \%$ of the required flight time for employability were changed to allow for simulation, that change would yield about half that cost for those training hours, or about a $5 \%$ total reduction in the financial burden to the student.

Monetary considerations are not the only advantages that flight simulation offers; simulation also offers the ability to train students in environments that would be impractical or unsafe in an aircraft. According to the 2009 Nall Report (Deres, Peterson, \& Vasconcelos, 2009), the four areas of pilot-related accidents in fixed wing aircraft that have the highest percentage of fatal accidents are: weather, takeoff and climb, maneuvering, and descent and approach. Not only do these have the highest fatal accident percentage of all pilot-related accidents, but they also have the highest lethality percentage. This means that if a pilot is involved in one of these accidents, that pilot and all of their passengers are more likely to have a fatality (Deres, Peterson, \& Vasconcelos, 2009). Simulation can help to prevent or mitigate the risks of these types of accidents by demonstrating how the accident chain can begin and how to remove oneself from it while not risking the lives of the student and instructor in the process.

Modern simulation equipment can expose pilots to weather hazards they are likely to encounter that would be unsafe to experience in an aircraft, such as thunderstorms and icing conditions. Simulators can also expose pilots to hazards that cannot be replicated in an aircraft without intentionally rendering the aircraft unairworthy, such as system or equipment failures. If this training were conducted as part of a visual flight curriculum, the accident rate could be reduced (Bürki-Cohen, Soja, \& Longridge, 1998; Ratvasky, Ranaudo, Barnhart, Dickes, \& Gingras, 2003). 
If safety will be improved and flight training costs can be reduced, then simulation will provide a tangible benefit to visual flight training. If this is not the case, then simulation would become a hindrance to the learning process. These issues must be carefully explored through the existing literature before recommendations of adoption can be made.

\section{Research Question}

What effect, if any, does the use of flight simulation have the time to solo of student pilots?

\section{Review of the Literature}

Solo flight is a rite of passage in the life of an aspiring pilot. This is the first time an individual will be the sole occupant of an aircraft, and truly be the final authority for the flight. The training process that leads a student to their first solo is not terribly long or difficult, relative to total flight training, but it does involve mastery of specific tasks and skills. There have been few studies that directly relate simulation training with the flight experience, measured in flight time required to achieve solo flight, but many studies have examined the effect of simulation on the time required to master the required tasks prior to the first solo.

Ortiz (1994) studied basic maneuver performance with simulation training when compared to aircraft only training. Ortiz found that the group that was given simulation training experienced a significant time savings over the control group. When a transfer effectiveness ratio was calculated, Ortiz found that the simulator training produced a result of $48 \%$ transfer.

Dennis and Harris (1998) also studied the effect of simulation on the mastery time of basic flight maneuvers when compared to a control group that did not receive simulation training. They found that those in the control group took longer to master the assigned flight maneuvers and had higher mental workloads while in the aircraft than did either of the two experimental groups that received simulation training before flying. Dennis and Harris (1998) concluded that the benefit of reduced time to master tasks for initial flight training was obvious, but the reason was not. In the experiment, the simulation equipment was not set-up to mimic the training aircraft, and the control inputs were entirely different than what was required in the aircraft. Dennis and Harris (1998) observed the reduced time to maneuver mastery, but could not attribute the time reduction to mechanical learning. Their explanation centered on the reduced workload experienced by the experimental groups when in the aircraft as compared to the control group. Their study argued that the simulation equipment used did not teach the students 
the mechanics of the maneuvers, but rather the concept and what to expect so that their workload was reduced when they were actually flying the assigned maneuvers.

Several studies have considered what the most vital part of pre-solo flight training is arguably the landing. These studies vary in research focus but all show that simulation can enhance landing training and make it more effective. Lintern and Walker (1991) found that students who were given simulation training in a simulation environment with moderate graphic fidelity performed best when learning to land. Lintern and Koonce (1991) studied the effect of visual magnification of the visual display of flight simulation equipment when related to landing. They found that properly applied magnification enhanced the simulation experience leading to better approaches to land. Lintern, Taylor, Koonce, Kaiser, and Morrison (1997) found that simulation experience with less graphic fidelity improved landing work in an aircraft over higher graphic fidelity systems and over training only in an aircraft. While these three studies have different results, they all reveal that simulation can be used effectively to train students toward landing an aircraft.

\section{Method}

\section{Participants}

Participants in this study were first semester flight students at Southern Illinois University Carbondale (SIUC), enrolled in a FAR Part 141 private pilot curriculum. Flight instructors from the SIUC instructional staff volunteered to conduct the training required by the study and those instructors approached their primary flight students about participation. Each student was given a letter stating the purpose of the study. Participation in the study was voluntary and approved for both experimentation and data collection by the SIUC Human Subjects Committee. All information collected remained confidential. The study covered three academic semesters: fall semester of 2010, spring semester of 2011, and fall semester of 2011. In all, 20 students participated, with 10 participants from the fall semester 2010, 4 from spring semester 2011, and 6 from the fall semester 2011. Of the 20 total participants, 2 did not solo at all and 6 completed their aircraft training in a Cessna 152 so they were not included in the results of this study.

\section{Research design}

Participants were given three hours of instruction in a Frasca 141 flight training device (FTD) with visual display prior to beginning training in an aircraft. Instruction was limited to 3 hours based on the course structure that the experiment was incorporated into and limited resource availability. The training was conducted at the beginning of flight training because the simulation training was intended to be an introduction to all the elements required for a first solo. The majority of the instruction received in the FTD focused on take-off and landing practice. The students received instruction on the basic sight pictures of a Cessna 172, aircraft control, straight-and-level flight, climbs, turns, descents, steep turns, slow flight, power on and off stalls, and take-offs and landings in 
the FTD. After completing the FTD training, the students completed the normal first semester curriculum of SIUC.

After all participants had completed their first solo, the total flight time in an airplane and calendar time to the first solo from the starting date were calculated and compared a historic data group using descriptive and inferential statistics. The historic data group consisted of all first semester SIUC flight students who reached the level of possibly soloing from the fall semester of 2006 through the fall semester 2011. Inferential statistics were calculated using SPSS version 20 and statistical powers were calculated using the $\mathrm{G}^{*}$ Power 3 computer program.

\section{Results}

The findings of this study addressed the research question "What effect, if any, does the use of flight simulation have the time to solo of student pilots?" The experimental group $(n=12)$ overall had a mean time to solo of 17.1 hours, mean days to solo of 77.3 days, median time to solo of 16.0 hours, and median days to solo of 79 days.

The historic group, which included data beginning with the fall 2006 semester, overall had a mean time to solo of 17.4 hours, mean days to solo of 86.1 days, median time to solo of 16.9 hours, and median days to solo of 77 days. The historic data were based on those in the historic group, excluding the experimental participants who successfully completed solo in a Cessna 172 aircraft $(n=134)$. A more complete representation of the data can be found in table 1 .

A two-tailed $t$-test revealed no statistical significance to the findings at the .05 level of hours $t(150)=.225, p=.823,1-\beta=.056, \eta^{2}=.000$; or days $t(150)=.784, p=.434,1$ $-\beta=.142 \eta^{2}=.004$. The sample met $t$-test assumptions of independent groups, ratio dependent variables, and similar variances for both flight hours and calendar days to solo. The small sample size made it difficult to determine normality of the dependent variables potentially violating a $t$-test assumption. The small sample size led to low statistical power increasing the chance of a Type II error.

The data were also examined within individual semesters to control for extraneous variables such as weather and aircraft availability. For the three academic semesters of the study, (a) fall 2010, (b) spring 2011, and (c) fall 2011, the experimental group data were as follows: mean time to solo: (a) 15.8 hours, 72.4 days; (b) 15.8 hours, 80.0 days; and (c) 21.3 hours, 89.7 days. For the same three academic semesters of the study, the non-participant group $(n=29)$, the subset of historic data from the semesters in which the study was conducted, data were as follows: mean time to solo: (a) 17.9 hours, 107.8 days; (b) 19.6 hours, 106.0 days; and (c) 16.5 hours, 83.9 days. A more complete and comprehensive data set is available in table 2. 
Table 1

Total Mean, Sample Standard Deviation, and Median Flight Hours and Calendar Days to Solo for Experimental and Historic Groups

\begin{tabular}{lccccc} 
& & \multicolumn{2}{c}{ Flight Hours } & \multicolumn{2}{c}{ Calendar Days } \\
Data Set & $n$ & Mean (SD) & Median & Mean (SD) & Median \\
\hline & & & & & \\
Participant $^{\mathrm{a}}$ & 12 & $17.1(4.2)$ & 16.0 & $77.3(37.5)$ & 79.0 \\
Historic $^{\mathrm{b}}$ & 134 & $17.4(3.8)$ & 16.9 & $86.1(27.2)$ & 77.0
\end{tabular}

Note. All data presented represents training in Cessna 172 aircraft.

${ }^{\mathrm{a}}$ Participant data collected from fall 2010 to fall 2011. ${ }^{\mathrm{b}}$ Historic data collected from fall 2006 to fall 2011.

Table 2

Mean, Sample Standard Deviation, and Median Flight Hours and Calendar Days to Solo for Experimental and Historic Groups by Academic Semester

Flight Hours

Calendar Days

$\begin{array}{lllll}\text { Data Set } & n & \text { Mean (SD) } & \text { Median } & \text { Mean (SD) }\end{array}$

Fall semester 2010

\begin{tabular}{llllcc} 
Participant & 8 & $15.8(2.2)$ & 15.1 & $72.4(31.4)$ & 67.0 \\
Non-Participant & 9 & $17.9(3.4)$ & 17.9 & $107.8(41.6)$ & 101.0 \\
\hline
\end{tabular}

Spring semester 2011

\begin{tabular}{llcccc} 
Participant & 1 & 15.8 & 15.8 & 80.0 & 80.0 \\
Non- Participant & 2 & $19.6(2.5)$ & 19.6 & $106.0(1.4)$ & 106.0 \\
\hline
\end{tabular}

Fall semester 2011

\begin{tabular}{lccccc} 
Participant & 3 & $21.3(5.3)$ & 19.0 & $89.7(17.0)$ & 99.0 \\
Non- Participant & 18 & $16.5(2.4)$ & 15.7 & $83.9(15.5)$ & 84.0 \\
\hline
\end{tabular}

Note. All data presented represents training in Cessna 172 aircraft.

Using a two-tailed $t$-test to compare the participants' mean times and days to solo did not result in any statistically significant differences at the .05 level for any semester in the study period. In fall 2010, $t(15)=1.551, p=.142,1-\beta=.313, \eta^{2}=.138$ for flight 
hours; and $t(15)=1.961, p=.069,1-\beta=.457, \eta^{2}=.204$ for calendar days to solo. In spring 2011 a $t$-test could not be completed because of the number of data points $(n=3)$. In fall 2011, $t(2.135)=1.531, p=.258,1-\beta=.423, \eta^{2}=.523$ for flight hours; or $t$ (19) $=.590, p=.562,1-\beta=.084, \eta^{2}=.018$ for calendar days to solo. The sample met $t$-test assumptions of independent groups, ratio dependent variables, and similar variances for both flight hours (except fall 2011) and calendar days to solo. For fall 2011 a $t$-test was calculated with equal variances not assumed. The small sample size makes it difficult to determine normality of the dependent variables potentially violating a $t$-test assumption. The small sample size led to low statistical power increasing the chance of a Type II error.

\section{Discussion}

Aviation is a costly industry in many respects with equipment that is costly to acquire, operate, and maintain. The costs of mistakes in aviation can be measured in terms of lives lost and equipment damaged. Proper use of simulation can reduce the overall monetary cost of flight training and recurrent pilot training as well as exposing pilots and flight crews to extraordinary circumstances that could be hazardous or fatal for a person exposed to them.

The question addressed by this study was "What effect, if any, does the use of flight simulation have the time to solo of student pilots?" As can be seen in table 1, there was no indication that flight simulation effects the flight time to solo for this study. The participant group had a lower mean time to solo in hours and days when compared to the historic, but this difference is not shown to be statistically significant at the .05 level through a two tailed $t$-test. This finding may be due to the very small participant sample $(n=12)$. A larger study may yield results with more statistical significance.

\section{Conclusions and Recommendations}

While the results of this study do not show a significant difference between simulation training and traditional training with respect to time to solo, the literature indicates that simulation is a valuable part of flight training. Simulation has a role to play in flight training, and it may even have a role to play in visual flight training. The problem is that there are too many unanswered questions about simulation training that must be addressed before any great strides can be taken in incorporating simulation into visual flight training industry wide. Further study involving a larger participant sample is needed to address what specific aspects of simulation training enhance basic flight maneuver training, the cost and benefit of simulation based visual flight training, the level of graphic fidelity that is adequate for visual flight training, and what role motion plays in enhancing student learning. Once these issues are addressed, there will be a more complete picture of the role that flight simulation can play in visual flight training. 


\section{Recommendations for Further Research}

1. Further research with an increase in study population is recommended to help determine the benefit of simulation in primary students.

2. Further experimental study is needed to fully understand how simulation training can affect a student's time to solo.

3. Further study is needed to determine what aspect of simulation training enhances basic flight skills so that focus can be placed in those areas during flight training.

4. Further study is needed is on the economics of simulation used in visual flight training to determine if there is a cost benefit to simulation training over traditional aircraft only training.

5. Further research is needed to determine what role motion and increased fidelity play in enhancing student progress in simulation training.

6. Further research is needed to determine the impact of the length of simulation training and the effect of integrating simulator instruction with aircraft training. 


\section{References}

Airfleet Training Systems, Inc. (n.d.) Student rates. Retrieved from http://www.airfleettraining.com/rates.html

Airline Transport Professionals. (n.d.). Flight training program guide. Retrieved from http://www.atpflightschool.com/downloads/ATP_Program_Index.pdf

Bradley, P., \& Postlethwaite, K. (2003). Simulation in clinical learning. Medical Education, 37(Supplement 1), 1-5. doi:10.1046/j.1365-2923.37.s1.1.x

Bürki-Cohen, J., Soja, N., \& Longridge, T. (1998). Simulator platform motion-The need revisited. The International Journal of Aviation Psychology, 8(3), 293-317. doi:10.1207/s15327108ijap0803_8

California Flight Academy. (2003). Airline Pilot Program. Retrieved from http://www.flycfa.com/index.php/airline-pilot

Dennis, K., \& Harris, D. (1998). Computer-based simulation as an adjunct to ab initio flight training. International Journal of Aviation Psychology, 8(3), 261-276. doi:10.1207/s15327108ijap0803_6

Deres, P., Peterson, B., \& Vasconcelos, K. (Eds.). (2009). 2009 Nall report--Accident trends and factors for 2008. Frederick, MD: AOPA Air Safety Foundation. Retrieved from http://www.aopa.org/asf/publications/09nall.pdf

Foushee, H. C. (1984). Dyads and triads at 35,000 feet. American Psychologist, 39(8), 885-893.

Lintern, G., \& Koonce, J. (1991). Display magnification for simulated landing approaches. International Journal of Aviation Psychology, 1(1), 59-72. doi:10.1207/s15327108ijap0101_5

Lintern, G., Taylor, H., Koonce, J., Kaiser, R., \& Morrison, G. (1997). Transfer and quasi-transfer effects of scene detail and visual augmentation in landing training. International Journal of Aviation Psychology, 7(2), 149-169. doi:10.1207/s15327108ijap0702_4

Lintern, G., \& Walker, M. (1991). Scene content and runway breadth effects on simulated landing approaches. International Journal of Aviation Psychology, 1(2), 117-132. doi:10.1207/s15327108ijap0102_3

Mid Island Air Service, Inc. (2009, July 1). Rental fleet specs \& prices. Retrieved from http://www.midislandair.com/COMPANY-INFO/Rental-Fleet-Specs-Prices.html 
Ortiz, G. (1994). Effectiveness of PC-based flight simulation. International Journal of Aviation Psychology, 4(3), 285-291. doi:10.1207/s15327108ijap0403_5

Oss, S. (2005). Computers with wings: Flight simulation and personalized landscapes. Journal of Science Education and Technology, 14(1), 117-122. doi:10.1007/s10956-005-2739-9

Padfield, G. D., \& White, M. D. (2003). Flight simulation in academia HELIFLIGHT in its first year of operation at the University of Liverpool. The Aeronautical Journal, 529-538.

Ratvasky, T. P., Ranaudo, R. J., Barnhart, B. P., Dickes, E. G., \& Gingras, D. R. (2003). Development and utility of a piloted flight simulator for icing effects training (NASA Technical Report Number: NASA/TM-2003-212166). Retrieved from http://gltrs.grc.nasa.gov/reports/2003/TM-2003-212116.pdf

St. Charles Flying Service, Inc. (2010). Aircraft rental \& instruction rates. Retrieved from http://www.stcharlesflyingservice.com/aircraft-rental-instruction-rates/ 